\title{
LA DIVERSIDAD DE ENFOQUES Y EL PROBLEMA DE LA ESPECIALIZACIÓN EN HISTORIA MEDIEVAL ${ }^{1}$
}

\author{
por \\ SUSAN REYNOLDS \\ Institute of Historical Research. London
}

No hay escasez de libros colectivos en historia medieval, pero incluso en un mercado abundante estos dos merecen ser leídos. No hay en ellos ningún artículo que no estimule la reflexión acerca de algún aspecto de la historia medieval. El poder en una de sus múltiples formas, dada su existencia en la mayoría de las relaciones humanas, no proporciona un vínculo temático fuerte para cada volumen, aunque los dos tienen otras características integradoras. Todos los artículos de Cultures of Power se centran más o menos en el siglo XII, mientras sobre Francia siete de los trece lo hacen completamente, y dos parcialmente, Property and Power cubre un período y área más amplios, dentro de los que la propiedad, junto al poder, es el elemento común que relaciona todas las contribuciones -mejor que en el otro libro lo hace "cultura", otro rasgo universal y mal definido de las sociedades humanas.

Cultures of Power comienza y concluye con breves piezas de su editor, quien explica que el libro se origino en un congreso celebrado en 1988, en el que un distinguido grupo de participantes planteo problemas acerca de «la experiencia humana del poder en el siglo XII... un período considerado de escaso gobierno", aunque uno en el que el poder estaba empezando a asumir "forma proto-estatales". Cuatro de los artículos se refieren a cuestiones acerca de la nobleza. En «Nobles y caballeros en Francia en el siglo xII" Theodore Evergates afirma que los contemporáneos sentendían claramente la naturaleza de la noblezas (pág. 34), que favorecían a los hijos mayores pero sin normas claras de primogenitura, y que la principal forma de ascenso a una élite territorial fue a través del matrimonio. Benjamín Amold sugiere

1 Bisson, Thomas N. (ed.), Cultures of Power: Lordship, Status, and Process in Twelfth-Century Europe. Pennsylvania University Press, Philadejphia 1995 (347 págs.); Davies, Wendy and Fouracre, Paul (eds.), Property and Power in the Early Middle Ages, Cambridge University Press, Cambridge 1995 (322 págs.). 
que los ministeriales no libres de Alemania debido a su utilidad en los ejércitos, llegaron entre 1050 y 1225 a ocupar una posición central dentro de la caballería y de ese modo se integraron en la aristocracia alemana. Otros dos artículos, bastante más breves, de Dominique Barthélémy y Georges Duby (como el de Philippe Buc) han sido traducidos del francés al inglés -aunque, a juzgar por algunos párrafos un tanto raros, no por el profesor Bisson. Barthélémy postula una distinción importante entre barons y vavassors, identificando los últimos con los "castral knights", es decir, con los caballeros que debían servicios de armas, pero que en el siglo XII se establecieron en sus propias tierras o señoríos. Duby da ejemplos de referencias eclesiásticas sobre mujeres nobles y anécdotas acerca de ellas que ilustran la amplitud de poder e influencia que podian ejercer. Aunque la historia del derecho no es una de las especialidades representadas en el libro, como señala Bisson en su introducción y sugiere en su conclusión al decir que "el derecho puede parecer menos central de lo que se supone habitualmenten, planea, sin embargo, sobre todos los artículos y es la preocupación principal de tres de ellos. El trabajo de Stephen White «Proponiendo y evitando la ordalia: estrategia y poder en la litigación del occidente francés, 1050-1110" es la mejor discusión sobre el uso práctico de la ordalía que yo he leído. R. C. Van Caenegem describe «Derecho y poder en el Flandes del siglo XII" en el contexto del derecho feudal que él, como otros participantes, entiende en el sentido que han hecho familiar los juristas profesionales e historiadores del derecho posteriores. Charles Duggan ( (Jueces papales delegados y la construcción del "nuevo derecho"») presta atención a los cambios en la práctica jurídica debidos a la profesionalización.

Dos artículos se ocupan de los rituales y ceremonias del poder. Geoffrey Koziol hace interesantes contrastes entre los rituales politicos en Francia, que promovieron respeto por la autoridad real, y el desorden y ridículo que a veces se produjeron en Inglaterra en ocasiones similares. Sugiere que los rituales de respeto y consenso no podían funcionar en el clima de conflicto y desconfianza que acompaño el incremento de poder y ambición del gobiemo real inglés. En «León: la iconografía de una capital» John W. Williams utiliza la evidencia de los tesoros y de los edificios, o resto de los mismos, que se conservan para mostrar como el palacio y la iglesia que construyeron y dotaron los reyes de León a fines del siglo XI y principios del siglo XII proclaman su poder y autoridad. Finalmente, cuatro artículos se centran directamente, aunque con diferencias significativas de puntos de vista e interpretación, sobre los escritos del momento que criticaban o justificaban el poder secular. John Van Engen considera que el señorío o dominium fue percibido en la edad media primeramente en términos de propiedad, y que en el siglo XI los reformadores eclesiásticos, y en particular los promotores de la Paz de Dios, proyectaron una imagen del mismo como la de «una violencia no sancionada ni limitada, ejercida más allá del orden divino» (pág. 219). Hacia el siglo XIII, pero no mucho antes eel estatus autónomo de los reinos terrenales había logrado el reconocimiento involuntario de los clérigos» (pág. 230). Philippe Buc, utilizando un material discutido más ampliamente en un libro reciente

Hispsania, LVII/I, núm. 195 (1997) 329-337 
y en un artículo anterior ${ }^{2}$, describe las formas bajo las que los comentaristas de la Biblia veían el poder secular. Comenzando con la famosa condena de Gregorio VII de los orígenes inicuos del poder secular, coincide con Van Engen en considerar que los reformadores eclesiásticos se resistieron al principio a su legitimación. Así, encuentra un igualitarismo potencialmente revolucionario en, por ejemplo, la disputa de Peter the Chanter y Stephen Laugthon sobre qué gobernantes debían consultar a la "gente común" (pág. 325). Laura Kendrick ve justificaciones clericales del poder y posesión nobles desde el siglo XI hechas sobre la base de "nociones de pureza y sangre noble» (pág. 278; cfr. pág. 270). Acusaciones de adulterio e incesto nobiliario en la poesía romance que estudia, especialmente en la de Marcabru, tienden, por tanto, a cuestionar Ia legitimidad del poder y privilegio nobiliarios. El artículo de C. Stephen Jaeger también utiliza la literatura romance junto con trabajos en latín. Comienza planteando el problema de juzgar el valor histórico de textos que ofrecen opiniones radicalmente opuestas, y señala las formas bajo las que cree que los romances corteses extendieron dichos valores a la sociedad laica. Finaliza con una serie de cuestiones que piensa necesitan más investigación: a partir de la evidencia de este análisis inicial hubiese sido interesante que él mismo hubiese ofrecido alguna.

Property and Power es el resultado, no de una conferencia, sino de una larga colaboración y discusión por un grupo de amigos que en 1986 publicaron un libro que hizo epoca The settlement of disputes in early medieval Europe. Utilizaron amplia documentación, apoyada por argumentos coherentes, para mostrar como los tribunales y asambleas, en la Alta Edad Media, aunque dominados por los poderosos, generalmente funcionaron, no por medio de «rituales bárbaros y decisiones arbitrarias" sino a través de discusiones, juicios colectivos y una aproximación pragmática a los testimonios ${ }^{3}$. Property and Power frustra ligeramente las expectativas de los que leyeron The settlement of disputes, debido probablemente a que los miembros del grupo tienen ahora compromisos más separados y divergentes y porque su nuevo tema no tiene una única línea argumental en sí mismo como la que hiciera de su primer libro tan magistral obra colectiva.

El que ahora comentamos comienza con una introducción de Timothy Reuter y Chris Wickham sobre el estado altomedieval y la estrecha relación entre propiedad y poder en la sociedad de la alta edad media; sobre el peligro de tomar Francia, y particularmente la Francia de los siglos $\mathrm{Ix}$ y x, como representación de toda Europa; sobre la necesidad de estudiar el derecho de propiedad, no a través de las teorías y normas legales enfatizadas (por ejemplo) por los historiadores del derecho (incluso por los que no se consideran a sí mismos como tales), sino a través de los "procedimientos y asunciones

2 L'ambiguité du livre: prince, pouvoir, et peuple dans les commentaires de la Bible (Paris et France du Nord, 1100-1330) (Paris, 1994); «Pouvoir royal et commentaires de la Bible», Annales ESC, 40 (1989), 691-713.

3 DAVIES, Wendy y FOURACRE, Paul (eds.), The settlement of disputes in early medieval Europe (Cambridge, 1986), 227, 221, et passim. 
prácticas locales» (pág. 10), y sobre el problema de las «inmunidades» que ven como signos de fortaleza más que de debilidad pública (pág. 7). Argumentan que prácticamente todas las inmunidades en el período estudiado fueron dadas a las iglesias y no explican la dispersión de jurisdicción entre los señores laicos. Cuatro artículos sobre este tema de las inmunidades constituyen la parte más coherente e interesante del libro. Paul Fouracre recoge testimonios que muestran que las primeras concesiones de inmunidad francas fueron destinadas a proporcionar moneda para pagar las luminarias de las iglesias que las recibieron. Wendy Davies muestra como en Gales lo que las historiadores llaman inmunidades parecen haberse originado en un tipo diferente de protección o santuario que las iglesias pretendían para sus tierras, que se transformarán en algo parecido a jurisdicciones independientes, quizás parcialmente bajo influencia inglesa, cuando posteriormente se desarrolló la autoridad real. Rosemary Morris estudia el desarrollo de exenciones de las obligaciones y jurisdicción imperiales en Bizancio en una forma que es reveladora no sólo acerca del gobierno bizantino sino también acerca de posibles fallos en el estereotipo con que compara su material. Patrick Wormald reabre una antigua discusión acerca de la extensión de la «jurisdicción privada" en la Inglaterra anterior a la conquista. Para este autor ninguna de las iglesias inglesas tuvo derechos jurisdiccionales a través de la inmunidad antes de 1066 y los que consiguieron después fueron copiados de Francia ${ }^{4}$. Sin negar el poder y jurisdicción superior que disfrutaron los reyes ingleses tanto antes como después de 1066, cabe todavía preguntarse si alguna de las grandes iglesias que tuvieron tribunales en el siglo xi en lo que parecen áreas de antiguo asentamiento no había estado ejerciendo jurisdicción al menos sobre los más humildes de sus habitantes desde mucho tiempo antes. No obstante, el argumento de Wormald, como los de Davies y Morris, al indicar la variedad de formas en que la jurisdicción podía desarrollarse en las sociedades medievales debería estimular a otros a investigar profundamente en el modelo tradicional con el que los historiadores han trabajado. Es una pena que nadie haya sido capaz de continuar una historia de las inmunidades francas donde la dejo Fouracre; la carencia de un trabajo sobre todo el periodo de la historia franca, a partir de la que se han tomado los estereotipos de la "anarquía feudal», deja un hueco en mitad del libro.

Hay, sin embargo, más temas que el de las inmunidades en el libro. David Ganz resume alguno de los problemas de las primitivas ideas cristianas sobre propiedad común planteadas por las iglesias. Ian Wood utiliza la historia de una donación de tierra perteneciente a la abadía de Saint-Wandrille para estudiar el significado de la precaria en la Galia merovingia y la forma en que Carlos Martel utilizó la propiedad de la iglesia para extender su poder. Janet Nelson ilustra con la disposición de propiedad por una viuda francesa en el siglo $\mathrm{x}$ los complejos problemas del poder, o de su carencia, de las mujeres, o

4 Pero el único caso de los señalados núm. 47 (Property and Power, 132) que concierne a la jurisdicción de un señor laico (el cual pudo traer la idea de jurisdicción señorial de Francía) se refiere a lo que fue de hecho el tribunal de un condado dividido.

Hispania, LVI/1, núm. 195 (1997) 329-337 
mejor de las mujeres nobles. Timothy Reuter muestra como el obispo Meinwerk de Paderborn (muerto en 1036) utilizó tanto su autoridad espiritual como sus tratos en tierra y bienes para mantener la riqueza y poder de su iglesia y sus buenas relaciones personales con los nobles locales. Chris Wickham afirma que los señores de Toscana comenzaron a transformar sus derechos sobre la tierra en algo parecido a un poder gubernamental en los siglos posteriores a la crisis de la autoridad carolingia. Aunque ve el cambio más en la forma que en el contenido, considera que supuso una gran diferencia para el desarrollo de lo que en el siglo XII fue aceptado como modelo de autoridad legitimada. La conclusión, de Davies y Fouracre, resume los argumentos de los participantes. Una de las sugerencias que hacen es que durante el período estudiado el poder sobre la tierra se transforma en poder sobre sus habitantes. Es un buen punto, pero se podría argumentar al revés. Aunque en una sociedad agraria establecida los dos son difíciles de distinguir, fue sólo en la baja edad media cuando los legistas profesionales comienzan a expresar claramente lo que había sido la autoridad política (poder sobre la gente) en términos de derechos sobre la propiedad.

Aún a riesgo de parecer que infravaloro estos dos estimulantes libros y de contenido amplio, el resto de esta reseña se centrará en algunas fronteras bastante lamentables entre los dos diferentes tipos de historia que ilustran. La primera, es una que parece marcar la historia del derecho como algo no muy reputable -0 ino muy de moda?--. En varios apartados de los dos libros (aunque Duggan, Van Caenegern, y White en uno, y quizás Wormald en el otro, estarán probablemente en desacuerdo) la "legal history" es vista como algo áridamente técnico. Para Reuter y Wickham tiene que ver con las «normas jurídicas" y la "teoría legal», no con las realidades sociales de costumbre y práctica. Pero esa es historia del derecho mala o inadecuada. La historia social o antropología histórica que atiende a las «asunciones prácticas» o a las «limitaciones del comportamiento humano en la practica (Property and Power, 10) sin tener en cuenta las reglas o normas detrás de ellas; o que no presta atención a los detalles de prácticas y procedimientos, aún aparentemente técnicos; o que asume que las palabras en los documentos siempre significan lo mismo, o interpola palabras que no están en ellos, es igualmente mala e inadecuada. Los mejores trabajos que tratan de propiedad y estatus en ambos volúmenes son buenos precisamente porque atienden tanto a las prácticas como a las normas y valores que parecen reflejar. En el contexto de un derecho consuetudinario, no profesional, tratar la distincion, como hacen todos, excepto Duggan, entre normas sociales y legales, es bastante irreal. Los que no quieren parecer historiadores del derecho pueden llamarse sociales si eso suena más de moda, pero el derecho consuetudinario es también derecho y eso es lo que importas.

Las partes menos convincentes de esos artículos son esas en las que las categorías del derecho posterior, interpretadas incluso por los historiadores

5 Ver, por ejemplo, Property and Power, 171, núm. 21.

Hispania, LVIJ/, núm. 195 (1997) 329-337 
del derecho, se imponen a la documentación. Cultures of Power incluye una gran cantidad de vasallos y feudos, y algunos alodios y vasvasores, que no se denominan así en las fuentes citadas o, si lo son, tal vez no eran lo que los escritos académicos sobre el derecho de feudos asumen que fueron ${ }^{6}$. Algunos de los argumentos acerca de nobleza y caballería también parecen estar influidos por la forma en que los juristas profesionales definirían y argumentarían acerca de los privilegios legales posteriormente. ¿Por qué palabras como nobilis y miles (o sus variantes romances equivalentes) habrían sido usadas coherentemente en el siglo XII? ¿Por qué los que las usaron no habrían hecho siempre o a menudo pensando en estatus social? $\mathrm{Si}$, como sugiere Evergates, caballero significo «la profesión de armas», ¿podría «soldado» ser tan buena traducción de miles como caballero? Si no, ¿por qué no? Depende de lo que nosotros queramos decir con soldado o caballero. ¿Estaríamos todos de acuerdo con el significado de "noblezaw? Si no, ¿qué queremos decir cuando decimos que la gente en el siglo XII tenía, o no, una clara concepción de ella?

Un uso parecido no suficientemente crítico de la historia legal tradicional está también implícito en alguna de las consideraciones de Ganz y Wood acerca de precaria en Power and Property. Aunque Wood alude al uso de la palabra por el documento más que a la concesión o la forma de tenencia ${ }^{7}$ la utilización que hace de expresiones como "tenencia precaria» o "tierra precarias, como otras partes de su artículo y del de Ganz, pueden ser entendidas como implicando que el término precaria representa lo que nosotros podríamos considerar una categoría de propiedad con derechos y obligaciones coherentes y definidos, lo que es ciertamente mixtificador. Las iglesias limitaban los derechos sobre la tierra que concedían, si a esas donaciones (o tierras donadas) las denominaban precaria, beneficios, feudos, libelli o cualquier otra cosa, era porque se pensaba que la propiedad de Dios y de los santos no podía ser alienada completa ni permanentemente. La naturaleza de las restricciones y de los términos utilizados variaba de iglesia a iglesia y en el tiempo. El significado de las palabras variaba de la misma forma. Variaron de nuevo, como

6 Vasallus parece poco frecuente en los textos en Latín del siglo XII, mientras la forma romance apenas parece utilizada en un sentido relativo y nunca para significar tenente de feudo (VENCKELEER, T., «Faut-il traduire vassal par vassal?" en Melanges de linguistique, de litterature et de philologie médiévales, offerts à J. R. Smeets (photog. typescript, Leiden, 1982, 303-316). Las propiedades de Artaud (Cultures of Power, 33), por ejemplo, no son llamadas feudos o alodios en las fuentes citadas. En el cartulario citado ibid, 60 núm. 23 (claramente copia del siglo xvııt de una compilación realizada en diversas fechas desde el siglo xi en adelante) vavassors (como vasallo) sólo aparece en los encabezamientos que pueden ser mucho más tardios que las listas mismas. Mi argumento sobre las implicaciones de esos términos, etc., en Fiefs and vassals (Oxford, 1994).

7 Property and Power, 46; cfi. e.g. Formulae (como citada ibid., núm. 72), 77-78, 81, 98-100, $169,191,199,591,235-236,242-243$, aunque el significado es más claro en algunos casos que en otros. La regla de Chrodegang, c. 31 parece implicar el mismo sentido: Patrología latina, 89, col. 114, 116: No he tenido acceso a la edición citada por Ganz (Property and Power, 23). Cfr. NitermeYER, J. F., y VAN DE KIEFT, C., Mediae Latinitatis Lexicon Minus (Amsterdam, 1976), 825-826, significados 1 y 2 .

Hispania, LVIl/1, núm, 195 (1997) 329-337 
señala Wood, cuando los laicos, por diferentes razones, hacían transferencias de tierras entre ellos sin todos los derechos. Usar los términos que los historiadores del derecho han elaborado a partir de otros sistemas de derecho, como «tenure» del derecho común inglés, o «usufructo» del derecho romano, tiende a postular categorías y formas de pensamiento que pueden ser equívocas en el contexto altomedieval. Estas observaciones críticas más bien pedantes y poco autorizadas no invalidan la discusión de Wood sobre las maniobras políticas de Carlos Martel, o alguno de los argumentos similares en otros artículos. Llevan, sin embargo, a sugerir que una actitud hacia la historia del derecho que sea a la vez más positiva y más crítica podría haberlos mejorado.

Otra frontera que necesita ser franqueada más a menudo es la que separa a quienes estudian la sociedad y política laicas y los que estudian las ideas políticas y sociales a través de tratados eclesiásticos o literatura romance. Buc y Van Engen se ocupan explícitamente de las visiones eclesiásticas por lo que puede ser inapropiado acusarlos de ignorar los valores y asunciones laicos. Pero las ideas eclesiásticas parecen bastante diferentes si se enmarcan más firmemente en el contexto de las ideas políticas que parecen haber sido aceptadas en la más amplia sociedad en la que vivían. Todas las sociedades, cristianas o no, de cultura escrita o no, tienen ideas, a pesar de lo poco que las articulen y argumenten, acerca de lo recto y de lo erróneo, de justicia y legitimidad. Los documentos regios y otros diplomas de la alta edad media, antes de que hubiera muchos letrados para escribir tratados, contienen gran cantidad de información acerca de la justicia y legitimidad del gobierno y de sus obligaciones, así como sobre los deberes de lealtad y obediencia de sus súbditos. Es difícil creer que cualquier rey poderoso permitiría que sus clérigos escribiesen algo que no quisiera decir (aunque permitiera alguna elaboración del lenguaje religioso), como lo es pensar que esos que dictan y firman cartas importantes actualmente permiten que lo hagan sus secretarios. Los clérigos que trabajaban en las cortes estuvieron probablemente $\longrightarrow$ o más probablemente- influidos por las asunciones de la sociedad laica y viceversa. No queda claro de dónde procede la opinión de Buc y Van Engen de una creencia eclesiástica general en la ilegitimidad del poder secular en los siglos XI y xII. Ni siquiera el mismo Gregorio VII adoptó generalmente esa línea, y en cualquier caso, como Jaeger señala (Cultures of Power, 293-4), la polémica es una guía muy pobre acerca de las asunciones y valores sociales ${ }^{8}$. En el mismo sentido, parece difícil deducir de las fuentes contemporáneas la idea de que la Paz de Dios fue dirigida contra el señorío secular, como algo diferente de los violentos infractores del derecho de cualquier clase?

8 Ver, por ejemplo la descripción clásica en CARLYLE, R. W. y A. J., A history of mediaeval political thought in the west (London 1903-1936), jii, 94-105, o LEWIs, E., Medieval political ideas (London, 1954).

9 Martindale, J., «Peace and War in Early Eleventh-Century Aquitaine», en Harper-BilL, C., y HarveY, R. (ed.), Ideals and Practice of Medieval of Medieval Knighood, 4 (1992), 147-176; cfr: GozTz, H. W., «Kirchenschutz, Rechtsbewahrung und Reform», Francia, 11 (1983) 193-239, especialmente 206-207, 225-226, 238. 
Lo que parece haber sido asumido de forma general fue que la autoridad política - es decir, el poder legitimado-pertenecía primero y sobre todo a los reyes, quienes gobernaban los reinos compuestos de uno o más pueblos o naciones, que en sí mismas formaban determinadas comunidades naturales. La autoridad real estaba legitimada por la necesidad de mantener el orden, jerarquía, justicia y costumbre. Se suponía que los reyes tenían que mantener la costumbre y la justicia mediante la consulta a la comunidad de sus súbditos representados por sus mayores (los miembros más importantes). Para los asuntos importantes, se consideraba deseable una consulta más amplia. No había nada intrínsecamente revolucionario, menos igualitario o democrático, en esto ni incluso en la propuesta de que los representantes del pueblo tuviesen derecho a aconsejar e incluso a reprobar a su gobernante, independiente de los controvertidos y duros argumentos que pudiera suscitar en la práctica ${ }^{10}$. Siempre debió haber cierta tensión entre las asunciones de los laicos - ¿y académicos? acerca de la autoridad y jerarquía real por un lado, y acerca de la justicia, comunidad y costumbre por otro. El testimonio de Buc de que Peter the Chanter y Stephen Laungton terminaron con esa oposición es extremadamente interesante pero, si es cierto que la autoridad legitimada siempre implicaba consulta, entonces sus observaciones acerca de ello parecen menos revolucionarias y probablemente menos igualitarias de lo que parece sugerir.

Como para la autoridad noble, que seguramente no fue primeramente legitimada por la nobleza de «sangre», sino parcialmente por referencia a oficios derivados supuestamente de los reyes, y parcialmente debido a que, en una sociedad jerárquica y basada en la costumbre, toda autoridad que era ejercida por un largo período de tiempo tendía a ser legitimada. La creencia en costumbre y jerarquía, de forma similar lieva un aura de antiguo origen, pero es difficil creer que esa creencia derivase del clero o tuviese mucho que ver con reglas acerca del matrimonio. Desde el siglo $\mathrm{xI}$ las enseñanzas de la iglesia sobre el matrimonio hicieron la herencia de la tierra por los hijos ilegitimos difícil pero parece haber tenido menos impacto sobre estatus o poder. La ilegitimidad importaba cuando se producía por el adulterio o fornicación de la mujer pero el estatus de los bastardos regios o nobles seguramente estaba todavía determinado por el reconocimiento y favor de sus padres. Esto no invalida las referencias de Kendrick acerca del poder de los poetas vernáculos para ridiculizar con sus ataques a la autoridad -lo mismo que otros comentarios ridículos del comportamiento sexual de los políticos modernos pueden minar su autoridad hoy. Pero el verdadero interés de lo que dice hace desear más comunicación entre los que estudian la sociedad la literatura y los que estudian otro tipo de evidencias acerca de la sociedad en que la misma fue escrita, de la misma forma que el interés de lo que Buc y Van Engen dicen demanda más rélación entre los que estudian a los profesionales y los que estudian la sociedad laica entorno a ellos.

10 Desarrollo estos argumentos en Kingdoms and communities in western Europe, 900-1300 (Oxford, 1984), los cuales he reelaborado en la introducción a una nueva edición (en prensa en 1996).

Hispania, LV11/1, núm. 195 (1997) 329-337 
Kendrick, Jaeger y Williams, al igual que Buc y Van Engen, nos dicen cosas que necesitamos saber los que no estudiamos arte y literatura medieval. $\mathrm{Si}$ esta reseña ha supuesto lo que ellos necesitan aprender de nosotros es porque los reseñantes sólo pueden hacer sugerencias de lo que saben o piensan que saben. Necesitamos más comunicación, no simplemente para poder discutir donde se equivocan, sino para que ellos puedan decírnoslo también. Todos nos beneficiaríamos si no temiésemos criticar el uso que cada uno de nosotros hacemos de las fuentes. Hay, desde luego, demasiados aspectos de la historia medieval para que podamos dominarlos. Todos tenemos lagunas, no sólo geográficas. La falta de comparación entre países es un problema serio. esta reseña está escrita por alguien que debe confesar que lamenta al mismo tiempo que se avergüenza de su casi completo desconocimiento sobre España. Es debido a que los artículos de estos dos libros son tan estimulantes que uno ocasionalmente se siente frustrado por la aparente falta de contacto entre disciplinas o áreas de especialización. El estímulo es, en todo caso, mayor que la frustración.

Traducción de Isabel Alfonso Centro de Estudios Históricos, C.S.I.C. 